\title{
The evolution of interdisciplinarity over 20 years of global change research by the IAI
}

Jeremy Pittman ${ }^{1 *}$, Holm Tiessen $^{2}$, and Elma Montaña ${ }^{2}$

${ }^{1}$ Environmental Change and Governance Group, University of Waterloo

200 University Ave W, Waterloo, ON N2L 3G1 Canada

jpittman@uwaterloo.ca

${ }^{2}$ Inter-American Institute for Global Change Research

Av. Italia 6201 - Ed. Los Tilos 102 - 11500 Montevideo, Uruguay

Holm Tiessen: htiessen@dir.iai.int

Elma Montaña: emontana@dir.iai.int

*Corresponding author

\begin{abstract}
Global change cuts across human and natural systems. Addressing it requires interdisciplinary research across the human and natural sciences. We show that the promotion of interdisciplinarity requires more than changing the requirements of funding calls. Successes have relied on leveraging the motivations of natural and social scientists by (1) providing space for experiential learning by researchers, (2) facilitating networking and teamwork across disciplines, (3) exposing researchers to new concepts or tools, (4) maintaining persistent mentorship and support for cultivating cross-disciplinary thinking, (5) connecting research to tangible problems, and (6) monitoring program calls, project selection and implementation. Here we present the experience of 20 years of motivating scientists to engage in interdisciplinary research, providing an environment for learning across disciplines, and structuring research programs to advance knowledge for decision making on global change.
\end{abstract}

\section{Introduction}

The Inter-American Institute for Global Change Research (IAI) was created in 1992 to stimulate global change research in the Americas and develop the region's capacity to address the challenges of global change [1]. Global change research must be interdisciplinary to address the pervasiveness and cross-cutting nature of global change and account for its effects on inseparable human-natural systems [2-8]. As such, a major component of the IAI's mandate is the promotion of interdisciplinarity.

Achieving interdisciplinarity in global change research requires breaking deeply engrained disciplinary barriers $[3,9]$. In the operating context of the IAI - and others $[4,10]$ - breaking these barriers has required a strategic and deliberate process of building upon and augmenting the motivations of researchers to participate in interdisciplinary projects. This process has involved modifying calls for proposals and developing funding mechanisms that provide incentives for interdisciplinary pursuits. However, the experience of the IAI shows that modifying the funding conditions in calls for proposals is not enough to achieve interdisciplinarity. Researchers have to be motivated and supported to (1) accept the additional challenges of conducting interdisciplinary research (e.g., communicating across disciplines) and (2) overcome the current academic incentive structure, which promotes individual, discipline- 
based work over teamwork [11]. The IAI's strategies have drawn on the desire of researchers to learn from different disciplines, tackle tangible and applied problems, and garner recognition within the international global change science community.

The purpose of this paper is to provide an overview of the evolution of interdisciplinarity based on the IAI's more than 20 years of experience. The paper focuses on four of the IAI's major funding programs: the Collaborative Research Networks (CRN) 1-3 and the Small Grants Program on the Human Dimensions (SGP-HD). We used a variety of methods to construct a meta-narrative on the IAI's funding and capacity building initiatives. Our approach leverages the expertise of the IAI, draws from the experience of researchers funded by the IAI, and synthesizes current opinion in the literature. The methods included surveys $(\mathrm{n}=76$; response rate $=28 \%)$, semi-structured interviews $(\mathrm{n}=23)$, and analysis of institutional documents. The survey, interview and document analysis is complemented, where appropriate, with examples drawn from the experience of IAI's directors.

\section{The evolution of interdisciplinary research funded by the IAI}

The IAI has always had a mandate towards interdisciplinary global change research. However, the IAI's research was initially mostly focused on natural sciences with social sciences lagging far behind [1]; an experience consistent with the field at the time [9,12]. It was thought that the role of science to confront global change was largely to provide knowledge of biophysical systems and processes that could later be applied in policy and practice. As a result, interdisciplinary research was mostly limited to collaboration within the natural sciences. In 1998, the IAI's first call under CRN 1 for "multinational and multidisciplinary collaboration", stated only that the "IAI encourages an interdisciplinary approach in all phases of the projects, including the involvement of social scientists where appropriate." Social science integration was not a firm requirement, and many projects had a natural science focus. That focus typically overlooked the interconnections and feedbacks between natural and social systems [8]. In addition, little attention was given to how the knowledge generated might move from the research community to the practitioner or policy-maker community $[13,14]$, or how it might be shaped for or by that user community.

With the recognition that research of global change inherently must involve natural and human science disciplines, and with changing demands on science outcomes, the IAI was tasked with further operationalizing interdisciplinary research $[15,16]$. By 2003, the need for interdisciplinarity in the call for proposals was much clearer, and the call optimistically stated that "all projects under CRN 2 will be highly interdisciplinary and collaborative efforts." Social science integration was a firm requirement, as the call stated that "the approach will be integrative - involving the natural and social sciences in a collaborative way". Additionally, the "extent of multinational/multidisciplinary collaboration" and "integration of natural \& social science" were included as proposal evaluation criteria. The IAI also encouraged "applied research that is policy relevant".

At the end of the proposal review process for CRN 2, selected projects were funded, generally without additional conditions to work on content. Unfortunately, only very few project activities were effectively linking natural and human dimensions, and the social science content of the IAI 

of the CRN 2 and SGP-HD calls served as lessons to the IAI and its grant panel. The next major network call, CRN 3, showed much greater commitment to achieving interdisciplinarity. This commitment is apparent based on three observations: (1) the scientific advisory committee decided that credible interdisciplinarity between human and natural sciences would be a criterion for success or failure; (2) the call became much more explicit on this condition; and (3) when, despite the greater clarity, most proposals were still found lacking, fewer proposals were funded, leaving funds for a second, more thematically focused call. These observations point to considerable learning by the IAI regarding ways of stimulating interdisciplinary research.

The IAI's efforts and ability to learn from its experience have resulted in a clear and traceable advancement of interdisciplinary research. The transition from CRN 2 to CRN 3 resulted in an increase in researchers from social disciplines; yet ecology remained the most frequently reported discipline. However, ecologists involved with the IAI are, for the most part, open to interdisciplinarity. During interviews and surveys, many researchers reported seeing the value of social science findings or changing the way they do research because of their engagement on interdisciplinary projects. Broto et al. [22] has theorized that researchers engaged in interdisciplinary projects are often grounded in their discipline, but pursue interdisciplinarity through interplay at the margins of existing disciplines. Similar interplay is occurring in IAI projects, as ecologists and other natural scientists interact more frequently with social scientists.

There has also been greater integration of social sciences into project conceptualization and methodologies (Figure 1). For instance, in CRN 1 just 33\% of survey respondents reported social science participation during the conceptual stages of research projects. This number almost doubled to $63 \%$ under CRN 2 and continued to grow to $87 \%$ under CRN 3. Additionally, qualitative methodologies were used more frequently. Only $50 \%$ of respondents reported using qualitative methods in CRN 1, while 91\% reported using them in CRN 3.

\section{<Insert Figure 1 about here>}

Figure 1. Discipline integration in project concepts and methodologies across IAI programs. Note: The SGP-HD call was directed towards social scientists; therefore the greater integration of social sciences within SGP-HD than CRN 3 is expected.

Additionally, the IAI has helped foster interdisciplinary research networks across the Americas (Figure 2) [1,24,25]. These networks, over time, built the trust required between researchers to pursue interdisciplinarity [23]. Notably, these networks have facilitated research collaboration within the Global South. The proportion of South-South collaborations increased from 52\% in CRN 2 to $67 \%$ under CRN 3. This change indicates an improved interest in, and capacity for, interdisciplinary research within the Global South. Such collaboration brings together countries with similar social and development concerns in the context of global change and facilitates the integration across natural and human sciences to tackle applied problems. 

engaged in these programs have faced three main challenges when implementing multinational, interdisciplinary research projects. First, researchers reported challenges framing research problems in an interdisciplinary, team-based way. Joint problem framing has been called for in the literature (e.g., [19]) and has demonstrated benefits (e.g., [20,21]), but it can take significant time to accomplish [18], which is difficult to accommodate in funding cycles and short-term research projects. Second, researchers have experienced difficulties finding compatible methods and integrating results across natural and social sciences. These difficulties match experience elsewhere [17,18]. Pahl-Wostl et al. [11] have proposed that creating innovative, interdisciplinary methods has been a major stumbling block for global change research in general. Third, researchers also face logistical challenges when implementing multinational projects. These logistical challenges may be technical in nature (e.g., having appropriate communication technologies) or can be a result of operating in different social and cultural contexts (e.g., different expectations within participating institutions).

\section{Lessons learned}

Despite the challenges, the IAI and the researchers it funds have persevered. Their success in advancing interdisciplinary global change research has relied upon the ability to learn from past programs and motivated researchers to overcome challenges. Awareness of the intellectual, technical and practical benefits of interdisciplinarity have been critical in this success. The IAI has actively sought to support researchers by (1) providing space for experiential learning, (2) funding and facilitating networking and teamwork across disciplines, (3) exposing researchers to new concepts or tools that support interdisciplinarity, (4) maintaining persistent mentorship and support for cultivating cross-disciplinary thinking, (5) connecting research to tangible problems, and (6) closely monitoring and providing feedback not only in program calls and project selection but also implementation.

\subsection{Providing space for experiential learning by researchers}

Researchers have been able to learn how to do interdisciplinary research by participating in IAIfunded projects. Approximately 56\% of researchers engaged in CRN 2, $70 \%$ in SGP-HD, and $80 \%$ in CRN 3 noted learning as a major motivating factor for their interdisciplinary pursuits. During the interviews, many researchers noted how their experiences on IAI-funded projects have allowed them to learn methods for conducting interdisciplinary research and to discover the value of findings from different disciplines. These shared learning experiences are extremely valuable for fostering the trust necessary for successful cross-disciplinary research [23]. Researchers also noted they have been able to apply the interdisciplinarity skills gained through past experience with the IAI within their current research programs.

\subsection{Exposing researchers to new concepts or tools that support interdisciplinarity}


Moving beyond disciplinarity requires updating the concepts or tools used by researchers [8,2630]. The IAI attempts to expose researchers to new concepts and tools by hosting a number of training programs on different interdisciplinary modeling techniques and the use of boundary concepts. Boundary concepts, described by Mattor et al. ([31]:95) as "fuzzy terms or phrases that refer to the same object, process, or quality in the construction of shared understanding of a given phenomenon", are gaining use within IAI-funded research. They are thought to be an effective tool for cross-disciplinary integration, although it can take significant time for them to yield benefits [31,32]. Similar experience is being observed within the IAI, where two boundary objects in particular - ecosystem services (sensu [8,33]) and social-ecological systems (sensu [34]) - have proven valuable despite requiring time to operationalize. The challenges lie in finding commonality when words or concepts are used quite differently by different researchers and within different disciplines [35]. Nonetheless, exposure of IAI researchers to new tools and concepts has leveraged their desire to learn, and facilitated their entrance into and continued engagement with interdisciplinary research.

\subsection{Facilitating networking and teamwork across disciplines}

The IAI has attempted to develop interdisciplinary networks through strategic interventions within its funding programs $[1,25]$. The SGP-HD funding program was designed to foster greater collaboration between natural and social sciences through a special call for proposals that had a social science focus, but also needed endorsement from natural science teams. The SGP-HD was conceived and launched in response to limited social science integration within CRN 2. Projects under SGP-HD were required to partner and engage with newly established CRN 2 projects tackling similar or compatible research problems. Although conceived as a remedial action, SGPHD was successful, with 70\% of SGP-HD and 60\% of participating CRN 2 researchers noting their ability to establish relationships across disciplines as a result of the program.

However, many researchers noted significant challenges in integrating the CRN 2 and SGP-HD projects, because the projects were developed separately. The key lesson from the SGP-HD experiment was the need to foster cross-disciplinary networks and interactions before and during project conceptualization and proposal development. This lesson was used in the subsequent call for the CRN 3 program. Several researchers noted that their experience under SGP-HD prompted them to apply for CRN 3 funding and to establish interdisciplinary relationships early in the development of their successful CRN 3 proposals. Newcomers to the IAI program were much less likely to aim for such integration despite the specific requirements of the CRN 3 call.

\subsection{Maintaining persistent mentorship and support for cultivating cross-disciplinary thinking}

An additional strategy of the IAI has been to provide support and mentorship for cultivating cross-disciplinary thinking. The IAI works with researchers at the proposal stage to advance and assist in further developing cross-disciplinary elements. In this way, the IAI provides researchers the opportunity and support to expand interdisciplinarity within proposed projects. Such support systems to advance interdisciplinarity have been called for in the literature (e.g., [36]), and the IAI's positive experience corroborates these calls.

\subsection{Connecting research to tangible problems}


Many researchers studying problems of global change hope that their research will have practical and useful outcomes $[10,12,21,37,38]$. Approximately $90 \%$ of researchers who engaged in IAI's programs noted the importance of having practical outcomes as a motivating factor for their participation in interdisciplinary research. The IAI helps build and leverage this motivation by (1) funding projects that engage or even include practitioners and policy makers and (2) supporting researchers through capacity building for science communication and policy connection. Many IAI-funded projects and training events include participation of individuals from outside academia (e.g., resource users, government officials). This approach helps facilitate interactions between individuals operating in both the research and applied domains and stimulates cross-fertilization of ideas regarding the goals of interdisciplinary projects and feasible ways of operationalizing findings. Additionally, the IAI has a section of its organization aimed specifically at capacity building, research communication and policy integration, which supports researchers in building skills in these areas [39-41]. Staff within this section work closely with researchers to improve their ability to tackle concrete problems and connect with actors in the applied domain. These strategies have helped the IAI motivate researchers towards what others call knowledge co-design and co-production, which help tackle the real-world problems associated with global change $[6,12,36,37,42-46]$.

\subsection{Monitoring program calls, project selection and implementation}

Close monitoring has helped the IAI improve interdisciplinary research. The improvements are visible in the analysis presented in the previous sections. However, these improvements caused significant strain, increased workloads and frustrations for all involved. Over 150 proposals were screened for their interdisciplinary quality under CRN 3, of which only 10 projects were funded. In addition, most initial project approvals were conditional on further strengthening interdisciplinarity and equity in participation between countries. Post approval revisions of project proposals took up to eight months and often required the inclusion of additional researchers and the re-assigning of budgets. Scrutiny of the project proposals and work plans had to go beyond scientific peer review to ensure interdisciplinarity. Examples of the level of scrutiny include: (1) asking for a reformulation of a project whose proposal abstract led with statements on social dimensions but had less than $10 \%$ of the budget assigned to social scientists; (2) checking on CVs of thesis supervisors to reveal studies in the social sciences that were to be supervised (likely inadequately) by professionals from the natural sciences; and (3) examining funding details for social science field work with communities, which had been lumped in with travel for ecosystem sampling without adequate, separate funding. In personal dialogues with researchers, the social scientist who had been 'called two weeks before the deadline' to quickly contribute to the proposal was a recurrent theme. Discussions to remedy such deficiencies were sometimes difficult because the largely disciplinary external peer reviews that were essential for determining fundability had ranked proposals as "excellent" without considering interdisciplinary integration. In addition, the IAI itself had to reorient its selection panel composition towards a more equitable representation of the disciplines, and panels had to provide not only an assessment of the basic fundability, but also guidance on how to remedy deficiencies in interdisciplinary integration.

\section{Discussion and conclusions}


Clearly much needs to be learned by funders, reviewers and scientists to improve interdisciplinarity. In the context of global change research, the natural sciences are just beginning to respond to these needs. But the mold of seeing global change largely as climate change and determined by physical phenomena has kept the social science community from responding to funding calls concerning global change. However, this pattern is breaking now and more progress can be expected on the task of integrating natural and social sciences.

We have demonstrated how the sustained efforts of the IAI helped facilitate the evolution of global change research in the Americas from a mostly disciplinary endeavor to an interdisciplinary pursuit. Originally, the IAI's projects (i.e., under CRN 1) were mostly natural science focused with minimal inclusion of the social sciences. Under CRN 2, there were more rules in place aiming to advance interdisciplinarity; however, there was little compliance with these rules. The SGP-HD was conceived as a remedial action to improve social science integration within CRN 2. Even though there were challenges, the interaction between SGP-HD and CRN 2 researchers initiated effective linkages between natural and social scientists. These linkages contributed to an improved integration and more interdisciplinarity within CRN 3.

The insights from the IAI's approach and experience have two broader implications. First, researchers, despite their good intentions, need support making the transition to interdisciplinary scholarship. Trying to induce interdisciplinary scholarship without due care and attention to capacity building is likely to fail. Moving from disciplinary to interdisciplinary research is a learning process for researchers and funding agencies. This learning process must be recognized and facilitated by relevant organizations and within funding mechanisms [36,47]. Second, stimulating interdisciplinarity requires a multifaceted, coordinated approach to addressing preexisting structural constraints (e.g., incentives for disciplinarity and individually conducted research [11]). The success of the IAI's approach has not depended on any single strategy, but results from different strategies coming together to motivate researchers to pursue interdisciplinarity in the face of ongoing challenges. The IAI has contributed significantly to advancing both interdisciplinary and transdisciplinary or user-oriented research. These advances are reported by researchers, who are actively pursuing natural-social science integration and actionable research outcomes. Global change research within the IAI's programs has evolved to become more interdisciplinary and more applied, and provides lessons that could be informative for funding organizations and other regions.

\section{Acknowledgements}

This work was carried out with the aid of a grant from the Inter-American Institute for Global Change Research (IAI) supported by the US National Science Foundation (Grant GEO1138881). We would like to give a special thanks to all researchers who participated in the survey and interviews. Their assistance is much appreciated and contributed significantly to the successful completion of the project. 


\section{Annotated references}

$* *$ Liu et al. 2015

This review paper proposes that a major advancement in recent science has been the recognition of the Earth as a system of subsystems, interconnected with various types of flows and relationships. In such a system, spillover effects between subsystems and tele-coupling over large distances are possible. However, greater integration between disciplines is required to provide science to promote global sustainability in an interconnected world.

* Mooney et al. 2013

Despite early attempts, limited interdisciplinarity across the natural and social sciences has been observed until recently in the field of Earth System Science. Barriers to interdisciplinarity are slowly being eroded. Emerging initiatives have the opportunity to learn from recent experience.

* Pahl-Wostl et al. 2013

Research methods have not kept pace with calls for more interdisciplinary global change research. Major stumbling blocks still exist in terms of finding appropriate interdisciplinary methods to study the problems associated with global change. Improved innovation within the scientific community is required to develop and advance interdisciplinary methods.

*Palsson et al. 2013

The challenges of addressing global change have been predominantly approached from a natural science perspective. Greater attention needs to be given to perspectives and insights from the social sciences and humanities in global change research. Additionally, the human and social sciences need to adapt to their new potential role at the forefront of global change research.

*Weaver et al. 2014

The social sciences have a key role to play in terms of making global change research actionable. Fundamental social science research can help span the boundary between global change research and multiple decision making contexts. Research partnerships and communities of practice that span the local-global will be key to unlocking the potential of the social sciences.

\section{References}

1. Lahsen M, Bustamante MMC, Swap R, McNie E, Ometto JPHB, Schor T, Tiessen H, Andelman S, Annegarn $\mathrm{H}$ : The contributions of regional knowledge networks researching environmental changes in Latin America and Africa: A synthesis of what they can do and why they can be policy relevant. Ecol. Soc. 2013, 18.

2. Palsson G, Szerszynski B, Sörlin S, Marks J, Avril B, Crumley C, Hackmann H, Holm P, Ingram J, Kirman A, et al.: Reconceptualizing the "Anthropos" in the Anthropocene: Integrating the social sciences and humanities in global environmental change research. Environ. Sci. Policy 2013, 28:3-13.

3. Holm P, Goodsite ME, Cloetingh S, Agnoletti M, Moldan B, Lang DJ, Leemans R, Moeller JO, Buendía MP, Pohl W, et al.: Collaboration between the natural, social and human sciences in Global Change Research [Internet]. Environ. Sci. Policy 2013, 28:25-35.

4. Cornell S, Berkhout F, Tuinstra W, Tàbara JD, Jäger J, Chabay I, de Wit B, Langlais R, Mills D, Moll P, et al.: Opening up knowledge systems for better responses to global environmental change. Environ. Sci. Policy 2013, 28:60-70. 
5. Tavoni A, Levin S: Managing the climate commons at the nexus of ecology, behaviour and economics [Internet]. Nat. Clim. Chang. 2014, 4:1057-1063.

6. Hackmann H, Moser SC, St. Clair AL: The social heart of global environmental change [Internet]. Nat. Clim. Chang. 2014, 4:653-655.

7. Kerstin K, Barth K: Inter- and Transdisciplinary Research for Planning Climate Change Adaptation Responses: The Example of Santiago de Chile. Interdiscip. Sci. Rev. 2014, 39:360-375.

8. Liu J, Mooney H, Hull V, Davis SJ, Gaskell J, Hertel T, Lubchenco J, Seto KC, Gleick P, Kremen C, et al.: Systems integration for global sustainability [Internet]. Science (80-. ). 2015, 347.

9. Mooney $\mathrm{H}$ a, Duraiappah $\mathrm{A}$, Larigauderie A: Evolution of natural and social science interactions in global change research programs. [Internet]. Proc. Natl. Acad. Sci. U. S. A. 2013, 110 Suppl :3665-72.

10. Moll P, Zander DIU: Implementation-oriented and transformative research-Lessons from a project on conservation and sustainable use of forest resources in Ethiopia [Internet]. Environ. Sci. Policy 2013, 28:82-91.

11. Pahl-Wostl C, Giupponi C, Richards K, Binder C, de Sherbinin A, Sprinz D, Toonen T, van Bers C: Transition towards a new global change science: Requirements for methodologies, methods, data and knowledge [Internet]. Environ. Sci. Policy 2013, 28:36-47.

12. Weaver CP, Mooney S, Allen D, Beller-Simms N, Fish T, Grambsch a. E, Hohenstein W, Jacobs K, Kenney $\mathrm{M}$ a., Lane $\mathrm{M}$ a., et al.: From global change science to action with social sciences [Internet]. Nat. Clim. Chang. 2014, 4:656-659.

13. Roux DJ, Stirzaker RJ, Breen CM, Lefroy EC, Cresswell HP: Framework for participative reflection on the accomplishment of transdisciplinary research programs [Internet]. Environ. Sci. Policy 2010, 13:733-741.

14. Buizer M, Ruthrof K, Moore S a, Erik J, Hardy G, Baudains C: Society \& Natural Resources : An A Critical Evaluation of Interventions to Progress Transdisciplinary Research. 2015, doi:10.1080/08941920.2014.945058.

15. Liverman D, Yarnel B, Turner BL: The Human Dimensions of Global Change. Oxford University Press; 2004.

16. Alonso B, Valladares F, Change G, Overview A: International Efforts on Global Change Research. Assessment 2008, doi:10.1007/978-1-4020-6358-9_1.

17. Boon WPC, Chappin MMH, Perenboom J: Balancing divergence and convergence in transdisciplinary research teams [Internet]. Environ. Sci. Policy 2014, 40:57-68.

18. Kladivko EJ, Helmers MJ, Abendroth LJ, Herzmann D, Lal R, Castellano MJ, Mueller DS: Standardized research protocols enable transdisciplinary research of climate variation impacts in corn production systems. J. Soil Water Conserv. 2014, 69:532-542.

19. Simon D, Schiemer F: Crossing boundaries: complex systems, transdisciplinarity and applied impact agendas [Internet]. Curr. Opin. Environ. Sustain. 2015, 12:6-11.

20. Diaz S, Demissew S, Carabias J, D I S, Joly C, Lonsdale M, Ash N, Adhikari JR, Arico S, Bartuska A, et al.: ScienceDirect The IPBES Conceptual Framework - connecting nature and people. 2015, doi:10.1016/j.cosust.2014.11.002.

21. Romero-Lankao P, Borbor-Cordova M, Abrutsky R, Günther G, Behrentz E, Dawidowsky L: ADAPTE: A tale of diverse teams coming together to do issue-driven interdisciplinary research. 
Environ. Sci. Policy 2013, 26:29-39.

22. Castán Broto V, Gislason M, Ehlers MH: Practising interdisciplinarity in the interplay between disciplines: experiences of established researchers. Environ. Sci. Policy 2009, 12:922-933.

23. Harris F, Lyon F: Transdisciplinary environmental research: Building trust across professional cultures [Internet]. Environ. Sci. Policy 2013, 31:109-119.

24. Melillo J, Rock A, Abreu A, Buizer J, Gallopin G, Gupta M, Virji H: Report of the External Review Committee assessment of the Inter American Institute for Global Change Research. 2007.

25. Swap RJ: The Inter-American Institute for Global Change Research: a resource for the Americas. Interciencia 2008, 33.

26. Hovelynck J, Dewulf A, François G, Taillieu T: Interdisciplinary knowledge integration through group model building: Recognizing dualities and triadizing the conversation. Environ. Sci. Policy 2010, 13:582-591.

27. Smith R, Davisb AS, Jordanc NR, Atwooda LW, Dalya AB, Grandya AS, Hunterd MC, Koidee RT, Mortensend DA, Ewingc $P$, et al.: Structural Equation Modeling Facilitates Transdisciplinary Research on Agriculture and Climate Change. Crop Sci. 2014, 54:475-483.

28. Girard C, Rinaudo J-D, Pulido-Velazquez M, Caballero Y: An interdisciplinary modelling framework for selecting adaptation measures at the river basin scale in a global change scenario [Internet]. Environ. Model. Softw. 2015, 69:42-54.

29. Nagabhatla N, Padmanabhan M, Kühle P, Vishnudas S, Betz L, Niemeyer B: LCLUC as an entry point for transdisciplinary research - Reflections from an agriculture land use change study in South Asia [Internet]. J. Environ. Manage. 2014, 148:42-52.

30. Bundy A, Chuenpagdee R, Cooley SR, Defeo O, Glaeser B, Guillotreau P, Isaacs M, Mitsutaku M, Perry I: A decision support tool for response to global change in marine systems: the IMBERADApT Framework. Fish Fish. 2015, doi:10.1111/faf.12110.

31. Mattor K, Betsill M, Huayhuaca C, Huber-Stearns H, Jedd T, Sternlieb F, Bixler P, Luizza M, Cheng AS: Transdisciplinary research on environmental governance: A view from the inside [Internet]. Environ. Sci. Policy 2014, 42:90-100.

32. Mollinga P: Boundary work and the complexity of natural resources management [Internet]. 2010, doi:10.2135/cropsci2009.10.0570.

33. Abson DJ, von Wehrden H, Baumgärtner S, Fischer J, Hanspach J, Härdtle W, Heinrichs H, Klein a. $M$, Lang DJ, Martens $P$, et al.: Ecosystem services as a boundary object for sustainability [Internet]. Ecol. Econ. 2014, 103:29-37.

34. Becker E: Social-ecological systems as epistemic objects. In Human-nature interactions in the Anthropocene: Potentials of Social-ecological systems analysis. Edited by Glaser, M., Krause, G., Ratter, B. and Welp M. Routeledge; 2012.

35. Uphoff $\mathrm{N}$ : ScienceDirect Systems thinking on intensification and sustainability: systems boundaries, processes and dimensions [Internet]. Curr. Opin. Environ. Sustain. 2014, 8:89-100.

36. Mauser W, Klepper G, Rice M, Schmalzbauer BS, Hackmann H, Leemans R, Moore H: Transdisciplinary global change research: The co-creation of knowledge for sustainability [Internet]. Curr. Opin. Environ. Sustain. 2013, 5:420-431.

37. Schmidt A, Striegnitz M, Kuhn K: Integrating regional perceptions into climate change adaptation: a transdisciplinary case study from Germany's North Sea Coast. Reg. Environ. 
Chang. 2012, doi:10.1007/s10113-012-0338-x.

38. Tiessen H, Brklacich M, Breulmann G, Menezes R: Communicating Global Change Science to Society. Island Press; 2007.

39. Shaman J, Solomon S, Colwell RR, Field CB: Fostering advances in interdisciplinary climate science. [Internet]. Proc. Natl. Acad. Sci. U. S. A. 2013, 110 Suppl :3653-6.

40. McCright AM, Sweeder RD, Urquhart GR, Zeleke A: Promoting interdisciplinarity through climate change education. Nat. Clim. Chang. 2013, 3:3-6.

41. Meadow AM, Ferguson DB, Guido Z, Horangic A, Owen G, Wall T: Moving Toward the Deliberate Co-Production of Climate Science Knowledge [Internet]. Weather. Clim. Soc. 2015, doi:10.1175/WCAS-D-14-00050.1.

42. Hurni H, Wiesmann U: Transdisciplinarity in Practice: Experience from a Concept-based Research Programme Addressing Global Change and Sustainable Development. GAIA - Ecol. Perspect. Sci. Soc. 2014, 23:275-277.

43. Görg C, Spangenberg J, Tekken V, Burkhard B, Thanh Truong D, Escalada M, Luen Heong K, Arida G, Marquez L, Bustamante J, et al.: Engaging Local Knowledge in Biodiversity Research: Experiences from Large Inter- and Transdisciplinary Projects. Interdiscip. Sci. Rev. 2014, 39:323341.

44. Serrao-Neumann S, Schuch G, Harman B, Crick F, Sano M, Sahin O, van Staden R, Baum S, Low Choy D: One human settlement: A transdisciplinary approach to climate change adaptation research [Internet]. Futures 2015, 65:97-109.

45. Bracken LJ, Bulkeley H a., Whitman G: Transdisciplinary research: understanding the stakeholder perspective [Internet]. J. Environ. Plan. Manag. 2014, doi:10.1080/09640568.2014.921596.

46. Fazey I, Bunse L, Msika J, Pinke M, Preedy K, Evely AC, Lambert E, Hastings E, Morris S, Reed MS: Evaluating knowledge exchange in interdisciplinary and multi-stakeholder research [Internet]. Glob. Environ. Chang. 2014, 25:204-220.

47. O'Brien K, Reams J, Caspari A, Dugmore A, Faghihimani M, Fazey I, Hackmann H, ManuelNavarrete D, Marks J, Miller R, et al.: You say you want a revolution? Transforming education and capacity building in response to global change [Internet]. Environ. Sci. Policy 2013, 28:4859. 
Figure1

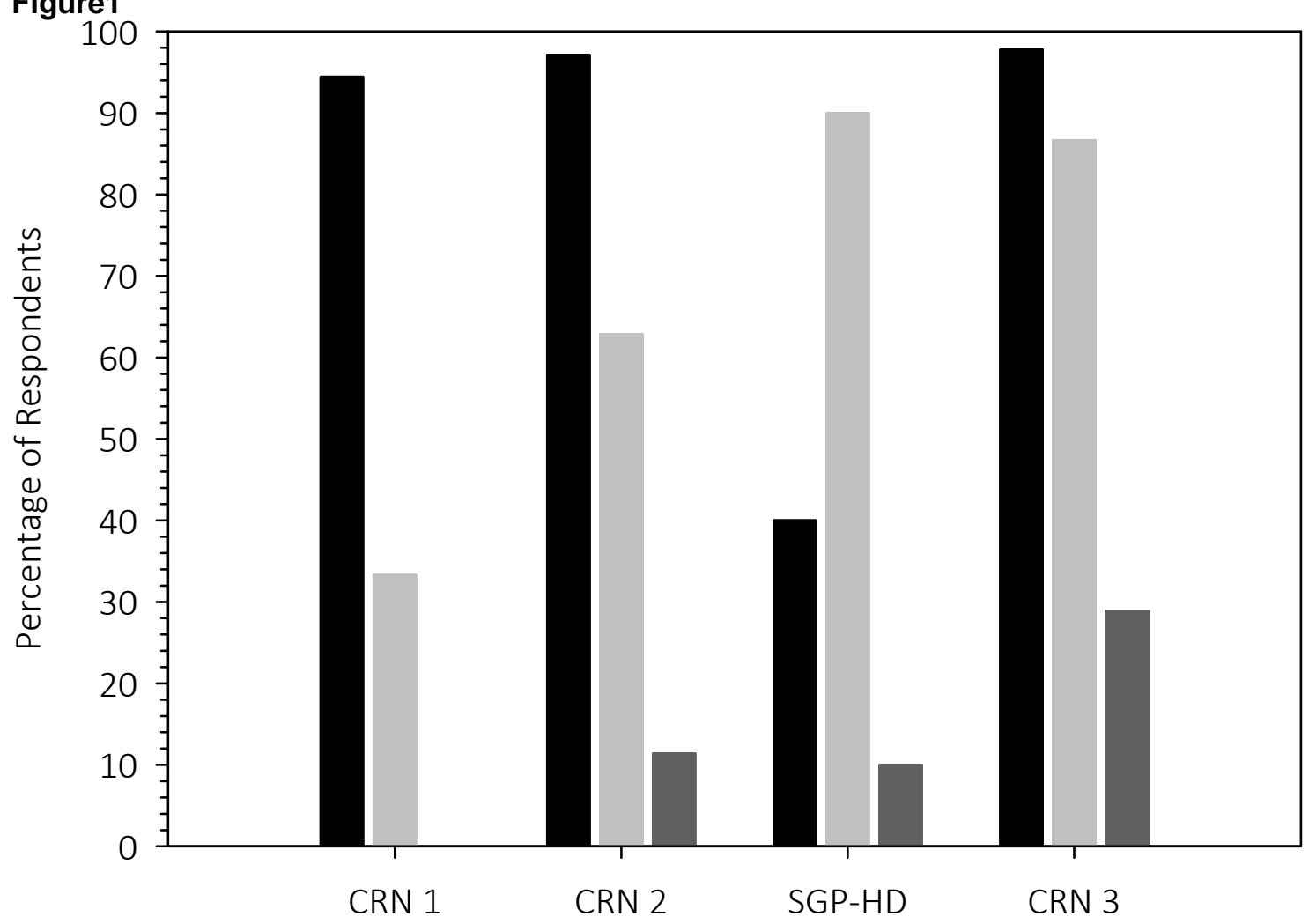

B. Disciplines informing methods

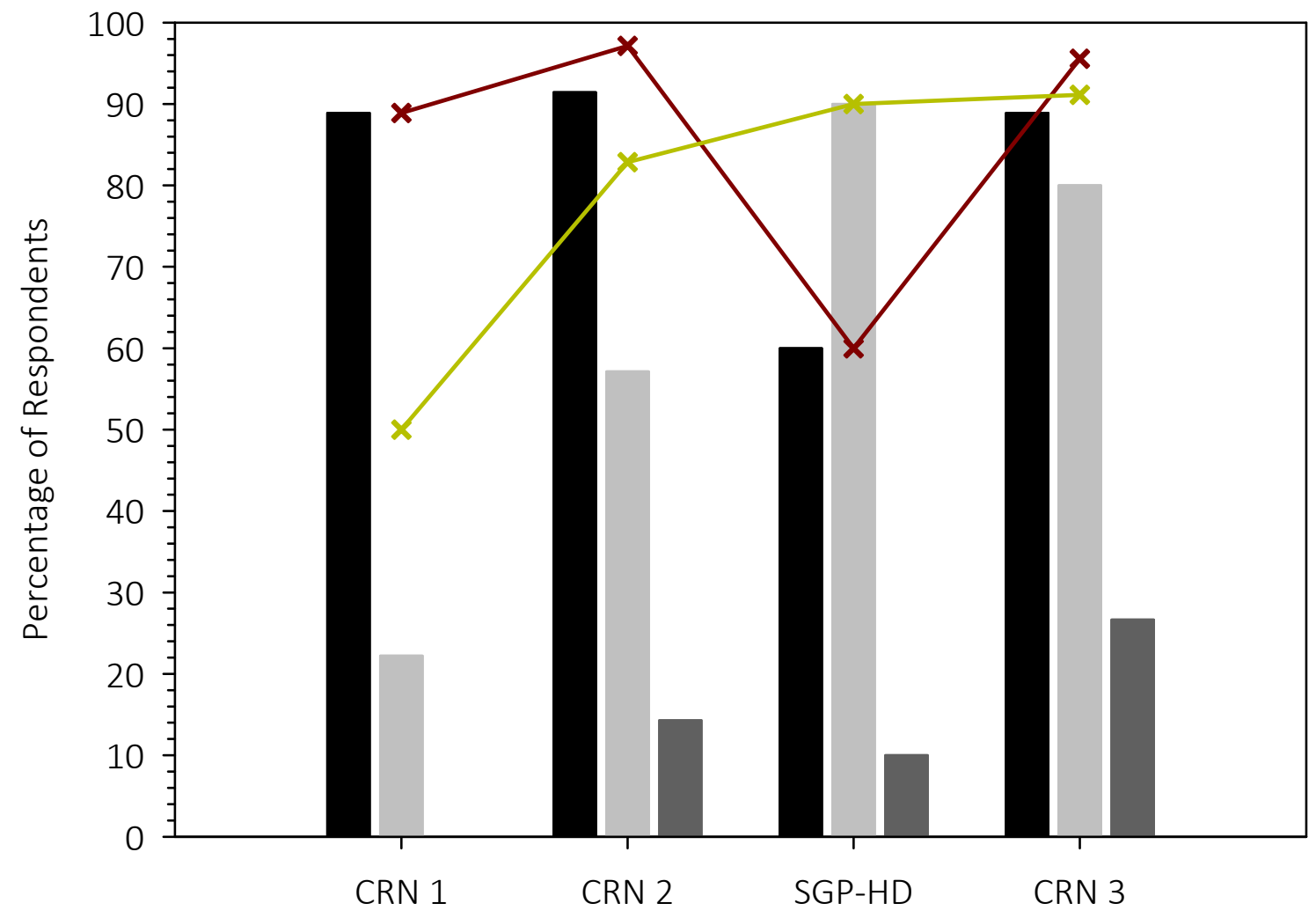

Natural sciences

Social sciences

Engineering

$\longrightarrow x$ Quantitative

$x$ Qualitative 
A. Organizational collaboration, CRN 2.

B. Organizational collaboration, CRN 3.
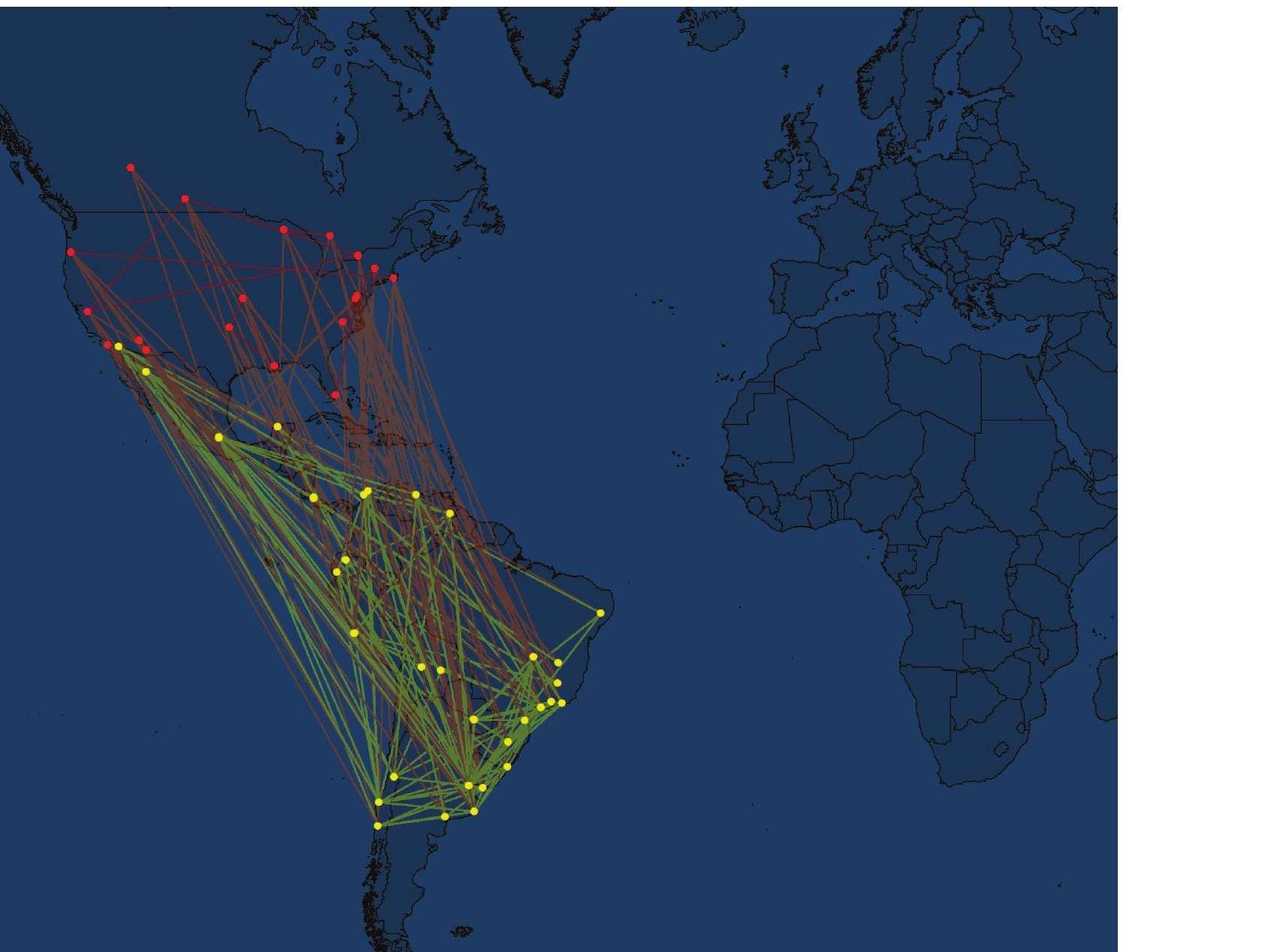